\title{
Preliminary Results of a RIGEE-funded Study: Pre-College Interactions, Early Expectations, and Perceived Barriers Among Entering Engineering Students
}

\section{Dr. Miguel Pando P.E., University of North Carolina, Charlotte}

Dr. Miguel A. Pando is currently an Associate Professor of Civil and Environmental Engineering at the University of North Carolina at Charlotte (UNCC), and was previously an Associate Professor of Civil Engineering at the University of Puerto Rico at Mayaguez (UPRM). In addition to his research in Geotechnical Engineering on the topics of soil-structure interaction and engineering characterization of geomaterials, Dr. Pando has been actively involved in teaching and mentoring students at both UPRM and UNCC, including 14 undergraduate civil engineering students through the NSF Louis Stokes Alliance for Minority Participation Program. Examples of his recent and ongoing engineering education research projects include the development of a Bridge to the Doctoral Program to attract Latinos to geotechnical earthquake engineering (NSF-NEES), use of a multi-institutional classroom learning environment for remote geotechnical engineering education (NSF-TUES), as well as a mixed methods study of the role of student-faculty relationships in the persistence and retention of underrepresented minority students in engineering (NSF-RIGEE). For the past three years, he has co-led (with co-author Dr. Tempest) the "Engineering for Development Workers" summer study abroad course at UNCC, focused on undertaking Civil Engineering projects in rural communities in Andean Peru.

Dr. Brett Tempest, University of North Carolina, Charlotte

Dr. Sandra Loree Dika, University of North Carolina, Charlotte 


\section{Preliminary Results of a RIGEE-funded Study: Pre-College Interactions, Early Expectations, and Perceived Barriers Among Entering Engineering Students}

One of the most significant challenges facing engineering education is the chronic problem of inclusion and retention of underrepresented minority (URM) groups, including women, certain racial and ethnic groups (African American, Latino, Native American) and students whose parents did not complete college (first generation college). This poster will present preliminary results from an NSF-RIGEE funded project whose aim is to study how formal and informal interactions with engineering agents may influence attitudes and intentions of URM students for enrollment and persistence, incorporating retention, social cognitive, and social capital theories. The poster will share results on entering engineering students' engineering-related interactions prior to college, perceived barriers during engineering studies, and early expectations of interactions with faculty and how these may differ based on student membership in an underrepresented group.

The study utilizes a mixed methods design, incorporating both questionnaire and focus group data. The questionnaire items were developed by the researchers utilizing existing instruments on perceived barriers to education and engineering-related interactions and were included as part of an annual questionnaire administered to the engineering freshman seminar at the institution under study. Seven items on likelihood to experience certain barriers (e.g., negative faculty attitudes, coursework difficulties) are rated from $1=$ strongly agree to $5=$ strongly disagree. For seven items on engineering-related interactions (e.g., visiting an engineering workplace), students indicate all of the adults with whom they interacted from five possible options (e.g., parent, teacher). About $47 \%$ of entering students responded to the questionnaire $(n=255)$, and are generally representative of the population in terms of race/ethnicity and gender. 
Focus groups are ongoing with small groups of entering African American and Latino engineering students. The focus group questions prompt discussion on what types of encouragement and support students received from family and educators during middle and high school to study engineering; expectations about interactions with professors prior to beginning classes; actual interactions with professors in and outside of the classroom; and perceptions about factors that affect how students and professors interact. One focus group was completed in October 2013, and it is anticipated that an additional one or two focus groups will be completed by December 2013.

The results to be presented on the poster will include tables highlighting the differences in number of engineering-related interactions prior to college and perceived barriers to engineering study, based on gender (male vs. female), generation in college (first generation vs. not first generation), and race/ethnicity (white vs. other race/ethnicity) using t-test comparisons. The themes from the focus groups on early expectations of interactions with professors and factors that affect how students and professors interact among first year African American and Latino engineering students will be named and illustrated through appropriate quotes from the focus group transcripts.

The results of the larger study will serve to help improve engineering orientation and first-year seminar experiences for URM and non-URM students, and to understand what types of precollege interactions may be linked to engineering enrollment. 